\title{
Methylene tetrahydrofolate reductase genotype and the risk and extent of coronary artery disease in a population with low plasma folate
}

\author{
S L Tokgözoğlu, M Alikaşifoğlu, İ Ünsal, E Atalar, K Aytemir, N Özer, K Övünç, Ö Usal, \\ $S$ Kes, E Tunçbilek
}

genotype was not an independent predictor of coronary artery disease, it was an important predictor of the extent of coronary atherosclerosis and plasma homocysteine, especially in the presence of plasma folate values below the median of the population. These findings may have important implications for folate replacement in patients with the TT genotype. (Heart 1999;81:518-522)

Keywords: coronary artery disease; vitamin B-12; folate; MTHFR mutation was determined by the Leaman score.

Results-Mean (SD) plasma homocysteine was 15.6 (10) $\mu \mathrm{mol} / 1$ in controls and 18.5 (11) $\mu \mathrm{mol} / 1$ in patients with coronary artery disease $(p>0.05)$. Plasma homocysteine concentrations above $15 \mu \mathrm{mol} / 1$ were a risk factor for coronary artery disease $(p=0.03$, risk ratio $2.1,95 \%$ confidence interval $(\mathrm{CI}) \mathbf{1 . 0 7}$ to 4.4). Homocysteine remained an independent risk factor on multivariate analysis when conventional risk factors were taken into account $(p=0.04)$. Homocysteine concentrations above $15 \mu \mathrm{mol} / 1$ were correlated with the extent of atherosclerosis $(p=0.04$, risk ratio $3.2,95 \%$ CI 1.3 to 8.2). Homocysteine had no effect on other lipid variables $(p>0.05)$. Plasma folate was $15.8(7.2) \mathrm{nmol} / 1$ in controls and $11.5(2.9) \mathrm{nmol} / 1$ in patients with coronary artery disease. Plasma folate concentrations below $12.9 \mathrm{nmol} / 1$ (5.7 $\mathrm{ng} / \mathrm{ml})$ conferred a risk for coronary artery disease ( $p=0.03$, risk ratio $2.42,95 \%$ CI 1.05 to 5.59). When the MTHFR genotype was determined, the TT genotype was present in $7.4 \%$ of patients and $5.2 \%$ of controls $(p>0.05)$. The prevalence of alleles was within the Hardy-Weinberg equilibrium (TT 7, CT 40, CC 53, $\chi^{2}=2.3, p=0.3$ ). The highest homocysteine concentrations were found in patients with the TT genotype and folate below the median of the population $(p=0.01)$. The extent of coronary atherosclerosis judged by the Leaman score was significantly higher in patients with the TT genotype $(p=0.03)$. Conclusions-Plasma homocysteine over $15 \mu \mathrm{mol} / 1$ was a significant risk factor for the presence and extent of coronary artery disease. The mean plasma folate of the population was low and correlated negatively with homocysteine. Although TT
Raised plasma homocysteine has emerged as a new independent risk factor for coronary artery disease. ${ }^{1}$ Evidence from several studies involving over 3000 patients has shown that a mild to moderate rise in plasma homocysteine is strongly associated with the development of atherosclerosis. ${ }^{2}$ The major determinants of plasma homocysteine concentrations are nutritional and genetic factors. ${ }^{3}$ A common single base pair exchange of cytosine to thymidine at nucleotide 677 of methylene tetrahydrofolate reductase (MTHFR) gene leads to thermolabile MTHFR with reduced enzyme activity, resulting in raised plasma homocysteine concentrations. ${ }^{5}$ It has been reported that this mutation is associated with the development of coronary artery disease. ${ }^{6}$ However, studies in different populations have not been in agreement about the importance of this mutation. ${ }^{7}$ It is claimed that the mutation may be important in subjects with lower folate concentrations. ${ }^{8}$

The Turkish population has a high prevalence of coronary artery disease, even though Turkey is a Mediterranean country and Turks have relatively low plasma cholesterol concentrations. ${ }^{9-11}$ We were therefore interested to examine the relations between plasma homocysteine, the thermolabile MTHFR mutation, and the development of coronary artery disease in this population.

\section{Methods}

SUBJECTS

The study population consisted of 242 consecutive patients undergoing coronary angiography for diagnostic purposes. The indication for angiography was either chest pain or the evaluation of the coronary arteries in patients scheduled for valve surgery. A detailed questionnaire was completed in all subjects before cardiac catheterisation, together with a physical examination, ECG, and 
Table 1 Distribution of risk factors among patients with coronary artery disease (CAD) and controls

\begin{tabular}{llllll}
\hline & $\begin{array}{l}\text { Controls } \\
(n=91)\end{array}$ & $\begin{array}{l}\text { CAD } \\
(n=151)\end{array}$ & $p$ Value & $\begin{array}{l}\text { Odds } \\
\text { ratio }\end{array}$ & 95\% CI \\
\hline Total cholesterol (mmol/1) & $5.36(1.22)$ & $5.57(1.17)$ & 0.09 & 1.78 & 0.93 to 3.41 \\
Triglycerides (mmol/1) & $1.70(0.79)$ & $1.99(0.90)$ & 0.009 & 3.10 & 1.33 to 7.23 \\
HDL (mmol/l) & $1.06(0.28)$ & $1.03(0.23)$ & 1.0 & 1.04 & 0.45 to 2.39 \\
LDL (mmol/1) & $3.31(0.85)$ & $3.75(0.75)$ & 0.01 & 2.60 & 1.23 to 5.46 \\
Total cholesterol/HDL & 5.04 & 5.37 & 0.015 & 2.70 & 1.25 to 5.84 \\
Smoking (\%) & 28 & 52 & 0.002 & 2.84 & 1.47 to 5.47 \\
Hypertension (\%) & 25 & 43 & 0.015 & 2.34 & 1.19 to 4.60 \\
Diabetes mellitus (\%) & 0.6 & 18 & 0.025 & 3.42 & 1.12 to 10.46 \\
Positive family history (\%) & 43 & 31 & 0.1 & 1.71 & 0.82 to 3.54 \\
\hline
\end{tabular}

CI, confidence interval; HDL, high density lipoprotein; LDL, low density lipoprotein.

chest $x$ ray. The questionnaire provided information about coronary risk factors such as smoking, diabetes mellitus, hypertension, and family history, as well as the presence of angina. Previous myocardial infarction was diagnosed according to conventional criteria described by the World Health Organisation (WHO). Patients with an acute illness such as myocardial infarction within the past three months, or a chronic disease such as chronic renal failure, psoriasis, and collagen vascular disease, were not included.

Cardiac catheterisation was performed by the Judkins technique. A left ventriculogram was performed in the $30^{\circ}$ right anterior oblique and $60^{\circ}$ left anterior oblique positions, followed by selective coronary angiography. Blinded assessment of coronary angiograms identified coronary artery disease as the presence of $>50 \%$ stenosis in any coronary vessel. According to this definition, 151 subjects were found to have coronary artery disease (patient group), while 91 had a completely normal coronary anatomy (control group). The mean (SD) age of the patient group was 57 (11) years and of the control group, 52 (11) years. The coronary score was determined subjectively by two different observers using the Leaman scoring system. ${ }^{12}$ In this system, the coronary arterial tree is divided into segments. Each lesion is given a score according to the location and severity of stenosis. Using this system, it is possible to score the extent of coronary atherosclerosis more accurately than it is when only the number of diseased vessels is stated.

\section{MEASUREMENT OF LIPIDS}

Blood was drawn in the fasting state on the day of coronary angiography. Plasma samples were analysed for fasting glucose, lipid profile, blood urea nitrogen, creatinine, and liver enzymes. The total cholesterol, high density lipoprotein (HDL) cholesterol, and triglycerides were determined by conventional methods.

Table 2 Distribution of genotypes among patients with coronary artery disease and controls

\begin{tabular}{|c|c|c|c|c|c|}
\hline & \multicolumn{3}{|l|}{ Genotypes } & \multicolumn{2}{|l|}{ Alleles } \\
\hline & $T T$ & $C T$ & $C C$ & $T$ & $C$ \\
\hline Coronary artery disease & $7.4 \%$ & $46.8 \%$ & $45.8 \%$ & $30.9 \%$ & $69.1 \%$ \\
\hline Controls & $5.2 \%$ & $43.1 \%$ & $51.7 \%$ & $26.7 \%$ & $73.3 \%$ \\
\hline $95 \%$ Confidence interval & 0.32 to 5.31 & 0.56 to 2.19 & 0.42 to 1.66 & \multirow{2}{*}{\multicolumn{2}{|c|}{0.37 to 1.62}} \\
\hline p Value & 0.701 & 0.765 & 0.622 & & \\
\hline
\end{tabular}

MEASUREMENT OF PLASMA HOMOCYSTEINE, VITAMIN B-12, AND FOLATE CONCENTRATIONS Total homocysteine in blood samples was determined by an immunoassay (Axis Biochemicals, Oslo, Norway). The assay method was based on enzymatic conversion of homocysteine to S-adenosyl-L-homocysteine, followed by quantification of S-adenosyl-Lhomocysteine by an enzyme linked immunoassay. ${ }^{13}$ Plasma vitamin B-12 and folate concentrations were both determined by microparticle enzyme immunoassay (Abbott Laboratories, Abbott Park, Illinois, USA).

\section{GENETIC ANALYSIS}

The polymerase chain reaction primers for the amplification of MTHFR have been described previously. ${ }^{14}$ The primers generate a 198 base pair (bp) fragment. The MTHFR polymorphism, a C to $\mathrm{T}$ substitution at bp 677, produces a Hinf I digestion site, which creates fragments of $175 \mathrm{bp}$ and $23 \mathrm{bp}$. The fragments are analysed by polyacrylamide gel electrophoresis.

\section{STATISTICS}

The frequencies of the allele genotypes among the cases and controls were counted and compared by the $\chi^{2}$ test with the values predicted by the Hardy-Weinberg equilibrium in the sample. Odds ratios were calculated as a measure of the association of the MTHFR genotype with the phenotype. For each odds ratio, two tailed $\mathrm{p}$ values and $95 \%$ confidence intervals (CI) were calculated. To determine the associations of the alleles with phenotype, multiple logistic regression analysis was performed. Leuvene's two tailed $t$ test was used to compare the means of variables.

\section{Results}

CHARACTERISTICS OF THE STUDY POPULATION Our study population consisted of 242 patients undergoing coronary angiography. Of these 151 were found to have coronary artery disease and 91 had normal coronary arteries. Of the patients with coronary artery disease, $58 \%$ had a previous myocardial infarction. None of the controls had a myocardial infarction. The distribution of several risk factors is shown in table 1 and reflects the expected differences in the prevalence of known risk factors for coronary artery disease. We found the following conventional risk factors to be significant risk factors for coronary artery disease in our study population (table 1): LDL cholesterol $(\mathrm{p}=0.01$, risk ratio $2.6,95 \%$ CI 1.23 to 5.46$)$, triglycerides $(\mathrm{p}=0.009$, risk ratio $3.1,95 \%$ CI 1.33 to 7.23 ), total cholesterol to HDL ratio $(\mathrm{p}=0.015$, risk ratio $2.7,95 \%$ CI 1.25 to 5.84), smoking $(\mathrm{p}=0.002$, risk ratio $2.84,95 \%$ CI 1.47 to 5.47 ), hypertension ( $\mathrm{p}=0.015$, risk ratio $2.34,95 \%$ CI 1.19 to 4.6 ), and diabetes mellitus ( $p=0.025$, risk ratio $3.42,95 \%$ CI 1.12 to 10.4). The patients with coronary artery disease had a mean (SD) Leaman score of 13.5 (12). 
Table 3 Distribution of plasma homocysteine levels according to genotype and plasma folate when population is divided according to median folate concentration

\begin{tabular}{lllll}
\hline & $C C$ & $C T$ & $T T$ & p Value \\
\hline Plasma homocysteine $(\mu \mathrm{mol} / \mathrm{l})$ & $14.5(7.0)$ & $16.9(9.0)$ & $23.3(15.0)$ & 0.001 \\
$\begin{array}{c}\text { Plasma homocysteine in patients } \\
\text { with folate }<12.9 \mathrm{nmol} / \mathrm{l}(\mu \mathrm{mol} / \mathrm{l})\end{array}$ & $15.2(8.0)$ & $19.5(10.0)$ & $28.4(15.0)$ & 0.01 \\
$\begin{array}{c}\text { Plasma homocysteine in patients } \\
\text { with folate }>12.9 \mathrm{nmol} / \mathrm{l}(\mu \mathrm{mol} / \mathrm{l})\end{array}$ & $14.0(6.0)$ & $14.5(8.0)$ & $12.0(4.0)$ & $\mathrm{NS}$ \\
\hline
\end{tabular}

Values are mean (SD).

PLASMA HOMOCYSTEINE, VITAMIN B-12, AND FOLATE CONCENTRATIONS

The mean (SD) homocysteine concentrations were 15.6 (10) $\mu \mathrm{mol} / 1$ in controls and 18.5 (11) $\mu \mathrm{mol} / 1$ in patients with coronary artery disease $(\mathrm{p}>0.05)$. Plasma homocysteine concentration above $15 \mu \mathrm{mol} / 1$ was found to be a significant risk factor for coronary artery disease ( $\mathrm{p}=0.03$, risk ratio $2.1,95 \%$ CI 1.07 to 4.4 ). On multivariate analysis when all other conventional risk factors were accounted for, plasma homocysteine concentrations remained an independent significant predictor of coronary artery disease risk $(\mathrm{p}=0.04)$. The homocysteine concentrations were not different between smokers and non-smokers, at 17 (9) $v$ 16 (9) $\mu \mathrm{mol} / 1, \mathrm{p}>0.05$. In addition, homocysteine concentrations above $15 \mu \mathrm{mol} / 1$ were an important risk factor for the severity of atherosclerosis as assessed by the Leaman score $(\mathrm{p}=0.014$, risk ratio $3.2,95 \%$ CI 1.3 to 8.2).

The plasma vitamin B-12 concentrations were 238 (100) pg/ml in patients with coronary artery disease and 244 (111) pg/ml in control subjects $(\mathrm{p}>0.05)$. There was no association between plasma vitamin B-12 and plasma homocysteine concentrations $(p>0.05)$. In addition, we found no association between the presence and extent of coronary artery disease and plasma vitamin B-12 concentrations $(\mathrm{p}>0.05)$.

The folate concentrations were 11.5 (2.9) $\mathrm{nmol} / \mathrm{l}$ in patients with coronary artery disease and 15.8 (7.2) nmol/1 in control subjects

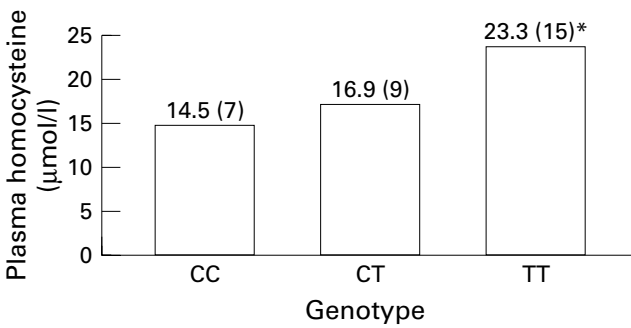

Figure 1 The distribution of plasma homocysteine concentrations according to genotype. ${ }^{\star} p=0.001, C C v$ $T T$.

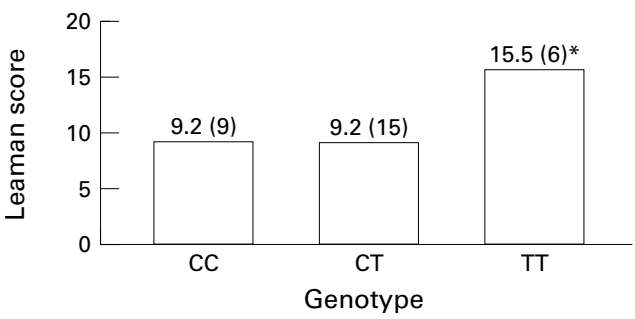

Figure 2 The distribution of Leaman scores according to genotype. ${ }^{*} p=0.03, C C v T T$.
Table 4 Predictors of coronary artery disease in multiple logistic regression

\begin{tabular}{ll}
\hline Variable & $p$ Value \\
\hline Smoking & 0.02 \\
Diabetes & 0.005 \\
Hypertension & 0.002 \\
LDL cholesterol & 0.003 \\
Total cholesterol/HDL ratio & 0.015 \\
Homocysteine & 0.04 \\
Folate & 0.03 \\
TT genotype & 0.25 \\
\hline
\end{tabular}

HDL, high density lipoprotein; LDL, low density lipoprotein.

$(\mathrm{p}=0.04)$. There was a significant negative correlation between plasma homocysteine and folate concentrations $(\mathrm{p}=0.03, r=-0.2)$. Plasma folate concentrations below the median conferred a risk of coronary artery disease (risk ratio $2.42, \mathrm{p}=0.03,95 \%$ CI 1.0 to 5.5). In addition, on subgroup analysis, smokers were found to have significantly lower folate concentrations than non-smokers $(\mathrm{p}=0.04)$.

When the effects of homocysteine on lipid variables were investigated, no effect was found on total cholesterol or triglyceride concentrations $(p>0.05)$. However, a weak negative correlation between HDL and plasma homocysteine was found $(r=-0.037, \mathrm{p}>0.05)$.

FREQUENCY OF ALLELES AND GENOTYPE

The distribution of genotypes is shown in table 2. TT genotype was present in $7.4 \%$ of patients with coronary artery disease and $5.2 \%$ of controls. The prevalence of alleles did not differ significantly (TT 7\%, CT 40\%, CC 53\%) from those predicted by the Hardy-Weinberg equilibrium $\left(\chi^{2}=2.3, \mathrm{p}=0.3\right)$.

The highest plasma homocysteine concentrations were found in the patients with the TT genotype compared with other genotypes (fig 1). On linear multivariate analysis, when corrected for vitamin B-12 and folate concentrations, TT genotype remained a significant predictor of plasma homocysteine ( $\mathrm{p}=0.004$, $95 \%$ CI 2.55 to 12.7 ). For further analysis, the group was divided according to the median plasma folate concentration of the population, which was $12.9 \mathrm{nmol} / 1$. Those with folate concentrations below the median and the TT genotype had the highest homocysteine concentrations ( $\mathrm{p}=0.01$ ) (table 3$)$. Furthermore, patients with the TT genotype had the highest Leaman scores compared with other genotypes (fig 2). The TT genotype was not associated with other conventional risk factors such as smoking, lipid concentrations, or hypertension $(\mathrm{p}>0.05)$. When the predictors of coronary artery disease were evaluated on multiple logistic regression analysis, in addition to conventional risk factors, plasma homocysteine and folate concentrations were independent predictors, whereas the TT genotype was not found to be an independent predictor of coronary artery disease (table 4).

\section{Discussion}

A growing body of published evidence suggests that raised concentrations of homocysteine are an independent risk factor for coronary artery 
disease. ${ }^{15}$ In a meta-analysis, a rise of $5 \mu \mathrm{mol} / 1$ of homocysteine was shown to be equivalent to a $0.5 \mu \mathrm{mol} / 1$ increase in total cholesterol in its effect on coronary risk. ${ }^{2}$ Our study was of interest because, despite a high prevalence of coronary morbidity and mortality in Turkey, the total cholesterol concentrations are relatively low and are not the major cause for the development of atherosclerosis. A recent epidemiological survey has shown that the prevalence of coronary artery disease is $4 \%$ in our adult population, with total cholesterol concentrations of 4.7 and $5.1 \mathrm{mmol} / 1$ for men and women, respectively. Furthermore, the prevalence of congenital neural tube defects associated with folate deficiency is significantly higher than in other countries. ${ }^{17}$ Several recent studies including the large study by the European COMAC group have shown that lower folate concentrations are associated with atherosclerotic vascular disease and increased coronary risk. ${ }^{18}{ }^{19}$ The WHO has proposed a lower limit of $13.6 \mathrm{nmol} / 1(6 \mathrm{ng} / \mathrm{ml})$ for folate concentrations. ${ }^{20}$ It has been shown that with values below $12.5 \mathrm{nmol} / 1(5.5 \mathrm{ng} / \mathrm{ml})$ homocysteine concentrations are actually increased. ${ }^{21}$ Most of our subjects in both the patient and the control groups had low folate concentrations according to these criteria. In the light of these findings, we thought that raised homocysteine concentrations might be an important risk factor for coronary artery disease in Turkey.

We found that plasma homocysteine concentrations above $15 \mu \mathrm{mol} / 1$ were a significant and independent risk factor for coronary artery disease, with a risk ratio of 2.1. This is in accordance with previous studies in other populations. ${ }^{22}$ Moreover, increased concentrations of homocysteine also predicted the extent of atherosclerosis as judged by the Leaman score. Several in vitro studies have shown that raised plasma homocysteine promotes both atherosclerosis and thrombosis by causing endothelial injury, smooth muscle cell proliferation, and low density lipoprotein oxidation. ${ }^{23-25}$ The effects of high plasma homocysteine concentrations on the risk of coronary artery disease have not been shown to be mediated by the known risk factors. ${ }^{26}$ Our findings support this theory. There was no association between increased homocysteine concentrations and the other risk factors examined in our study. One weak inverse association with HDL was statistically nonsignificant. The two predictors of plasma homocysteine concentrations were found to be the TT genotype and plasma folate.

The importance of the TT genotype has been questioned in previous studies conducted in well nourished populations. ${ }^{27}$ Our subjects had significantly lower folate concentrations than similar groups studied in the United States and Australia. A recent study in a US population showed that the TT genotype increased homocysteine concentrations only in patients with folate concentrations below the median. ${ }^{28}$ Our study is one of the very few to look at genotype and plasma homocysteine, vitamin B-12, and folate concentrations simul- taneously in the same population. We chose to evaluate subjects assessed by coronary angiography to be sure that the control group did not have substantial but clinically silent coronary atherosclerosis. In our population, the TT genotype significantly predicted the extent of atherosclerosis in patients with coronary artery disease. However, this genotype was not an independent predictor of the presence of coronary artery disease, but an important predictor of plasma homocysteine concentrations. In this group of Turkish patients, the highest plasma homocysteine concentrations were present in patients where the TT genotype and folate deficiency coexisted.

This may have important clinical implications. Dietary and environmental factors may modify hyperhomocysteinaemia arising from genetic causes, offering the potential for therapeutic intervention. Recent studies have shown that an increased intake of vitamin B-6, vitamin B-12, and folate can reduce plasma homocysteine concentrations, even in patients with the TT genotype. With $1000 \mu \mathrm{g}$ folate supplementation, a $21 \%$ reduction in homocysteine level has been observed. ${ }^{29}$ However, it remains to be determined whether treatment of hyperhomocysteinaemia will lead to a reduction in vascular disease. Although no appropriate studies have been undertaken so far, a decrease in homocysteine concentrations with vitamin supplementation, especially in people with the TT genotype, may prevent atherosclerosis in these individuals. Randomised trials are needed to determine the effect of vitamins in decreasing vascular disease risk.

This project was funded by the Turkish Society of Cardiology.

1 Montalescot G. Homocysteine: the new player in the field of coronary risk. Heart 1996;76:101-2.

2 Boushey CJ, Beresford SA, Omenn GS, et al. A quantitative assessment of plasma homocysteine as a risk factor for vascular disease: probable benefits of increasing folic acid cular disease: probable benefits of
intakes. $7 A M A$ 1995;274:1049-57.

3 Meleady RA, Mulcahy DA, Graham IM. Genes, greens and homocysteine. Heart 1996;76:103-4.

4 Daly L, Robinson K, Tan KS, et al. Hyperhomocysteinemia: a metabolic risk factor for coronary heart disease determined by both genetic and environmental influences? Q F Med 1993;86:685-9.

5 Kang SS, Wong PW, Susmeno A, et al. Thermolabile methylene tetrahydrofolate reductase: an inherited risk factor for coronary artery disease. Am f Hum Genet 1991;48:536-45.

Morita H, Taguchi J, Kurihara H, et al. Genetic polymorphism of 5,10-methylene tetrahydrofolate reductase as a risk factor for coronary artery disease. Circulation 1997;95: 2032-6.

7 Bockxmeer FM, Mamotte CDS, Vasikaran SD, et al. Methylene tetrahydrofolate reductase gene and coronary artery disease. Circulation 1997;95:21-3.

8 Jacques PF, Bostom AG, Williams RR, et al. Relation between folate status, a common mutation in MTHFR, and plasm

9 Onat A, Dursunoglu D, Sansoy V. Relatively high coronary death and event rates in Turkish women. Relation to three major risk factors in 5 year follow up of cohort. Int 7 Cardiol 1997;61:69-77.

10 Onat A, Şenocak M. Relative risk of factors for coronary heart disease in a population with low cholesterol levels. Int f Cardiol 1994;43:51-60

11 Onat A, Avcı GS, Soydan I, et al. Türk eriskinlerinde kalp sağlığının dünü ve bugünü. Istanbul: Karakter Color Matbaas1, 1996.

12 Leaman DM, Brower RW, Meester GT, et al. Coronary atherosclerosis: severity of the disease, severity of angina pectoris and compromised left ventricular function. Circulation 1981;63:285-99.

13 Frantzen F, Faaven AL, Alfheim I, et al. Enzyme conversion immunoassay for determining total homocysteine in plasma or serum. Clin Chem 1998;44:311-16. 
14 Frosst P, Blom R, Milos P, et al. A candidate genetic risk factor for vascular disease: a common mutation in factor for vascular disease: a comm

15 McCully KS. Vascular pathology of homocysteinemia: implications for the pathogenesis for arteriosclerosis. Am $\mathcal{f}$ Pathol 1969;56:111-28.

16 Tunçbilek E, Alikaşifoğlu M, Akdalı B, et al. Türkiyede konjenital malformasyon sıkl1, dağıllım, risk faktörleri ve yenidọganların antropometik değerlendirilmesi. Ankara: TUBİTAK Matbaasi, 1996

17 Boduroğlu K, Alikaşifoğlu M, Anar B, et al. The 677 CT mutation of the MTHFR gene is not a risk factor for neural tube defects in the Turkish population. Arch Dis Child 1998;78:F235.

18 Robinson K, Arheart K, Refsum H, et al for the European COMAC group. Low circulating folate and vitamin $B_{6}$ concentrations. Risk factors for stroke, peripheral vascular disease and coronary artery disease. Circulation 1998;97: 437-43.

19 Morrison HI, Schaubel D, Desmeles M, et al. Serum folate and risk of fatal coronary heart disease. $7 A M A 1996 ; 275$ : 1893-6.

20 Food Nutrition Board, National Research Council. Folic acid: biochemistry and physiology in relation to human nutrition requirement. Washington DC: National Academy of Sciences, 1977.

21 Pancharuniti N, Lewis CA, Sauberlich HE, et al. Plasma homocysteine, folate and vitamin $\mathrm{B}_{12}$ concentrations and risk factor for early onset coronary artery disease. Am F Clin Nutr 1994;59:940-8.
22 Stampfer MJ, Malinow R, Willett W, et al. A prospective study of plasma homocysteine and risk of myocardial infarction in US physicians. $\mathcal{F} A M A$ 1992;268:877-81.

23 Harker LA, Ross R, Slichter SJ, et al. Homocysteine induced arteriosclerosis: the role of endothelial cell injury and platelet response in its genesis. F Clin Invest 1976;58:731-41.

24 Tsai JC, Perella MA, Yoshizumi M, et al. Promotion of vascular smooth muscle cell growth by homocysteine: a link to atherosclerosis. Proc Natl Acad Sci USA 1994;91:6369-73.

25 Nishinaga M, Ozawa T, Shimada K. Homocysteine, a thrombogenic agent suppresses anticoagulant heparan sulfate expression in cultured porcine aortic endothelial cells. f Clin Invest 1993;92:1381-6.

26 Tonstad S. Correlates of plasma total homocysteine in patients with hyperlipidemia. Eur f Clin Invest 1997;27: $1025-9$

27 Omenn GS, Beresford SAA, Motulsky AG. Preventing coronary heart disease: B vitamins and homocysteine. Circulation 1998;97:421-4.

28 Folsom AR, Nieto J, McGovern PG, et al. Prospective study of coronary heart disease incidence in relation to fasting plasma homocysteine, related gene polymorphisms and B vitamins. The atherosclerosis risk in communities study. vitamins. The atherosclerosis

29 Malinow MR, Nieto FJ, Kruger WD, et al. The effects of folic acid supplementation on plasma total homocysteine are modulated by multivitamin use and MTHFR genotypes. Arterioscler Thromb Vasc Biol 1997;17:1157-62. 